\title{
VARIAÇÃO SAZONAL DO TEOR DE MATÉRIA GRAXA EM SARDINHA VERDADEIRA (Sardinella aurita) NOTA PRELIMINAR
}

\section{Masayuki Furuya}

Nesta nota apresenta-se os resultados das análises feitas em caráter de sondagem, a fim de fixarmos os critérios mais acertados a serem adotados na apuração da posição mais provável de uma curva que indica a variação sazonal do teor de gordura.

\section{PARTE EXPERIMENTAL}

1) Material. - As amostras procedem do Mercado Municipal e entrepostos particulares em São Paulo. Algumas foram adquiridas em Santos. Tôdas elas, porém, carecem de informação quanto ao local onde foram pescadas. As datas assinaladas nas tabelas são aquelas de aquisição e não de captura. A tabela I resume dados referentes aos materiais analisados.

2) Métodos. - A extração da matéria graxa foi feita pelo método de Sohxlet. Os exemplares foram decapitados, escamados, desprovidos de nadadeiras e filetados, analisando-se apenas a porção mole restante, desprovida de coluna vertebral. As espinhas deixadas na carne não foram removidas. Assim foi feito a fim de evitar a demora da moagem, realizada num moinho manual, sem o que era preciso desobturar freqüentemente os furos do disco à saída do moinho. Nestas condições, os teores encontrados, referidos ao pêso do peixe integral, não incluem o óleo extraível das partes desprezadas, mormente da cabeça.

Trabalho do Instituto Oceanogrảico (Secâo de Tecnologia Industrial). 


\section{RESULTADOS}

1) Teor total — Os resultados reunidos na tabela II não incluem o óleo contido na cabeça e demais resíduos ósseos ou cartilaginosos, o que não deve ser esquecido nas considerações que seguem.

Para têrmos melhor idéia da flutuação dos resultados, transplantamos os resultados da tabela II para um diagrama (fig. 1).

Vê-se nêle que existe um trecho nitidamente ascendente no período janeiro-março. De abril a julho poderá haver um patamar ou uma curva de pequena flutuação. No têrço final do ano os dados são escassos e nada de positivo poderá ser afirmado. Os dois últimos pontos do diagrama, embora representem teores baixos de matéria graxa, correspondem a exemplares miúdos, pouco desenvolvidos no porte, como se vê na tabela I.

2) Gordura abdominal - A fig. 1 mostra, ainda, a flutuação da matéria graxa encontrada na carne. A diferença para o

TABELA I

Histórico do material analisado

\begin{tabular}{|c|c|c|c|c|c|c|}
\hline \multirow{2}{*}{$\begin{array}{c}\text { Amostra } \\
\text { ne }\end{array}$} & \multirow{2}{*}{$\begin{array}{l}\text { Data de } \\
\text { aquisição }\end{array}$} & \multirow{2}{*}{$\begin{array}{c}\text { No de } \\
\text { exemplares }\end{array}$} & \multirow{2}{*}{$\begin{array}{c}\text { Pêso total } \\
\text { (g) }\end{array}$} & \multirow{2}{*}{$\begin{array}{l}\text { Pêso médio } \\
\text { p/exemplar } \\
\text { (g) }\end{array}$} & \multicolumn{2}{|c|}{$\begin{array}{l}\text { Pêso da porcão } \\
\text { mole analisada }\end{array}$} \\
\hline & & & & & $\mathrm{g}$ & $\%$ \\
\hline 1 & $24 / 1 / 55$ & 27 & 1.888 & 74,1 & 1.084 & 57,41 \\
\hline 2 & $15 / 2 / 55$ & 22 & 1.650 & 75,0 & 850 & 51,51 \\
\hline 3 & $25 / 2 / 55$ & 39 & 1.800 & 46,2 & 1.200 & 66,67 \\
\hline 4 & $16 / 3 / 55$ & 30 & 1.850 & 61,7 & 950 & 51,35 \\
\hline 5 & $25 / 3 / 55$ & 29 & 1.900 & 65,5 & 1.030 & 54,21 \\
\hline 6 & $30 / 3 / 55$ & 36 & 1.360 & 37,8 & 750 & 55,56 \\
\hline 7 & $5 / 4 / 55$ & 9 & 920 & 102,0 & 569 & 61,84 \\
\hline 8 & $18 / 4 / 55$ & 24 & 1.500 & 62,5 & 790 & 52,67 \\
\hline 9 & $9 / 5 / 55$ & 27 & 1.600 & 59,25 & 850 & 53,13 \\
\hline 10 & $20 / 5 / 55$ & 27 & 1.500 & 55,6 & 763 & 50,86 \\
\hline 11 & $25 / 5 / 55$ & 33 & 1.770 & 53,6 & 935 & 52,82 \\
\hline 12 & $1 / 6 / 55$ & 34 & 1.820 & 53,6 & 960 & 52,74 \\
\hline 13 & $25 / 6 / 55$ & 22 & 950 & 43,2 & 525 & 55,26 \\
\hline 14 & $10 / 8 / 55$ & 24 & 1.570 & 65,4 & 850 & 54,14 \\
\hline 15 & $26 / 8 / 55$ & 49 & 1.100 & 22,4 & 575 & 52,27 \\
\hline 16 & $14 / 8 / 55$ & 30 & 1.145 & 38,1 & 660 & 57,64 \\
\hline
\end{tabular}


TABELA II

\begin{tabular}{|c|c|c|c|c|c|c|}
\hline \multirow{2}{*}{$\begin{array}{c}\text { Amostra } \\
n^{\circ}\end{array}$} & \multirow{2}{*}{ Carne $(\%)$} & \multirow{2}{*}{ Viscera (\%) } & \multicolumn{2}{|c|}{ \% s/ porção mole } & \multirow{2}{*}{$\begin{array}{c}\begin{array}{c}\mathrm{s} / \text { pêso } \\
\text { total }\end{array} \\
\begin{array}{c}\text { oleo da } \\
\text { carne }\end{array}\end{array}$} & \multirow{2}{*}{ Oleo total } \\
\hline & & & $\begin{array}{l}\text { Oleo da } \\
\text { carne }\end{array}$ & $\begin{array}{l}\text { Oleo das } \\
\text { visceras }\end{array}$ & & \\
\hline 1 & 1,60 & 5,47 & 1,35 & 2,57 & 0,78 & 1,66 \\
\hline 2 & 2,10 & 5,15 & 1,53 & 1,41 & 0,80 & 1,56 \\
\hline 3 & 4,50 & 12,90 & 3,27 & 3,52 & 2,00 & 3,47 \\
\hline 4 & 7,60 & 22,55 & 6,77 & 2,56 & 3,39 & 4,77 \\
\hline 5 & 7,77 & 24,43 & 7,10 & 2,29 & 3,88 & 5,28 \\
\hline 6 & 5,78 & 26,69 & 5,35 & 1,93 & 3,01 & 5,78 \\
\hline 7 & 7,24 & 14,90 & 6,10 & 2,44 & 3,93 & 6,52 \\
\hline 8 & 6,78 & 28,70 & 6,30 & 2,10 & 3,22 & 4,82 \\
\hline 9 & 8,80 & 41,91 & 7,70 & 5,24 & 4,11 & 7,12 \\
\hline 10 & 7,21 & 32,84 & 6,36 & 5,01 & 3,41 & 5,73 \\
\hline 11 & 7,43 & 33,89 & 6,62 & 3,68 & 3,58 & 6,04 \\
\hline 12 & 7,90 & 40,95 & 7,20 & 3,64 & 3,52 & 5,80 \\
\hline 13 & 5,85 & 28,77 & 5,32 & 2,61 & 2,93 & 4,74 \\
\hline 14 & 6,81 & 33,40 & 5,72 & 5,34 & 3,01 & 6,07 \\
\hline 15 & 3,76 & 10,94 & 2,89 & 2,53 & 1,57 & 2,35 \\
\hline 16 & 3,23 & 6,62 & 2,45 & 1,61 & 1,51 & 2,20 \\
\hline
\end{tabular}

teor total representa a gordura encontrada no conteúdo abdominal, em sua maioria representada pela gordura branca depositada por entre as dobras do tubo digestivo. Os valores numéricos constam da tabela II. Por êles se vê que o conteúdo abdominal, de março a agôsto, encerra teor superior a $20 \%$ em gordura, atingindo até cêrca de $40 \%$ do seu pêso.

Pelo exposto se vê que a curva de flutuação do teor de gordura não está perfeitamente caracterizada. Deve-se levar em conta a gordura existente nas partes desprezadas desta série de análises e não deve ser ignorada a diferença do estado de desenvolvimento dos peixes. É indispensável colher materiais de portes diferentes que houver no mercado na mesma data ou em datas muito próximas, desde que, dentro das nossas possibilidades, não está ao nosso alcance conhecer o local e data certa da captura. 


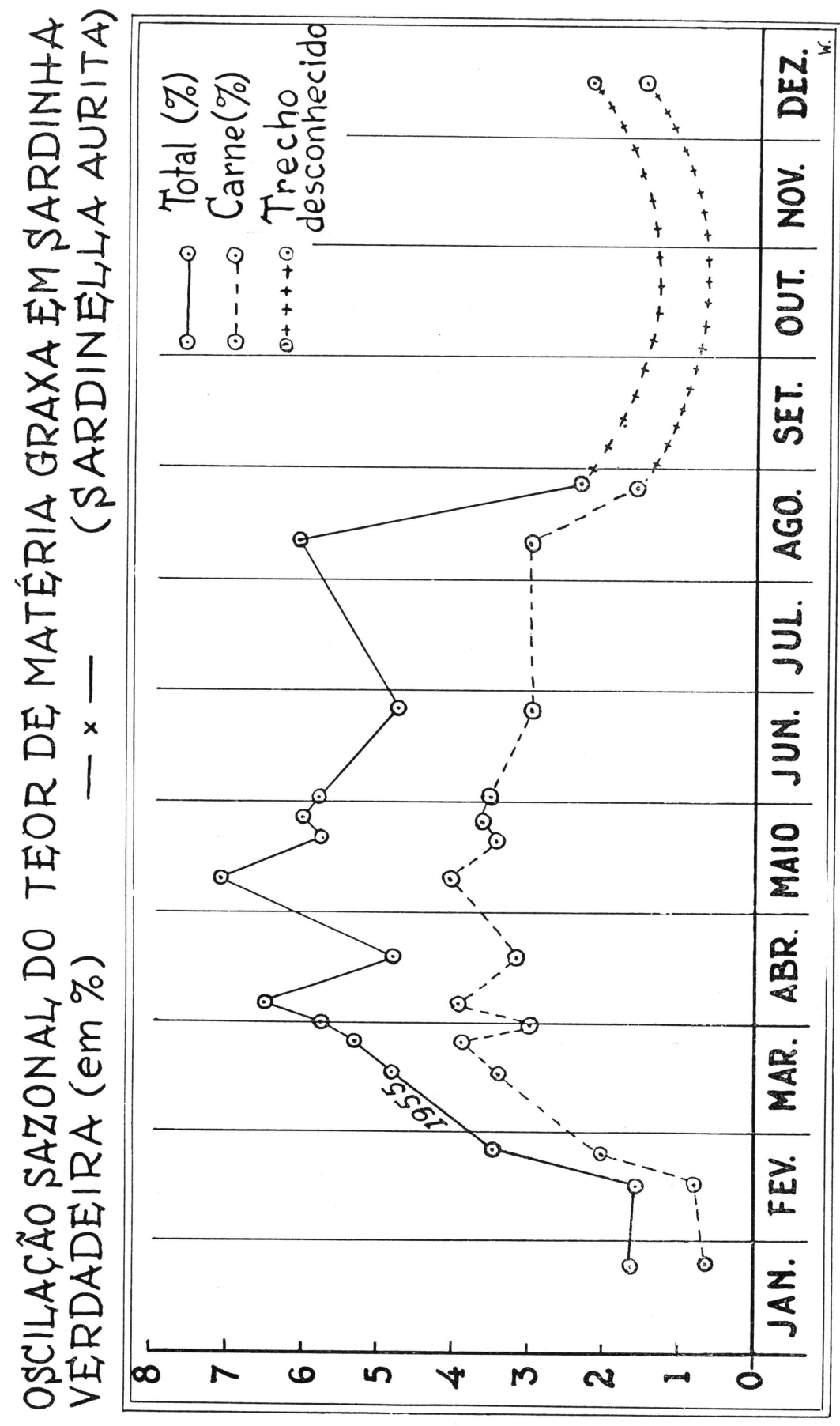

